\title{
Democratization of Intrapreneurship and Corporate Entrepreneurship within the McKinsey's Three Horizons Innovation Space.
}

\author{
Evangelos Markopoulos ${ }^{1}$, Vasu Aggarwal $^{1}$, Hannu Vanharanta ${ }^{2}$ \\ ${ }^{1}$ HULT International Business School, Hult House East, 35 Commercial Rd, E1 1LD, London, \\ United Kingdom \\ ${ }^{2}$ University of Vaasa, School of Technology and Innovations, Wolffintie 34, 65200 Vaasa, \\ Finnland \\ evangelos.markopoulos@faculty.hult.edu,vaggarwal2016@student.hult.edu, \\ hannu@vanharanta.fi
}

\begin{abstract}
Knowledge democratization is essential to innovation strategy formulation and execution. It is the culture in which organizational strategies are embraced to create shared added-value. This paper provides a framework through which companies can develop democratic corporate entrepreneurship and intrapreneurship operations and strategies. The Company Democracy Model is used as the method based on which knowledge democratization is built by providing a structured path to satisfy the pre-conditions, post conditions and evolution of such initiatives. In this attempt, the Company Democracy Model integrates the McKinsey's 3 horizon model for organizational growth. The integration of the two models creates a knowledge based corporate entrepreneurship and intrapreneurship transformation strategy, supported by phases, stages, and goals. Furthermore, this integration is projected in a 3-dimensional space where the horizontal business development, of the McKinney 3 Horizons, affects the vertical organizational maturity, of the Company Democracy Model, through innovation development inside or outside the organization.
\end{abstract}

Keywords: Company Democracy · Corporate Entrepreneurship · Intrapreneurship $\cdot$ Horizons $\cdot$ Knowledge $\cdot$ Innovation $\cdot$ Strategy $\cdot$ Management.

\section{Introduction}

In the world of uncertainty, maximizing innovation and staying competitive is crucial for organizational sustainability and operations. The existing management systems empower employees of high educational, social and rank level to explore innovation opportunities on establishing corporate entrepreneurship and intrapreneurship projects and initiatives within the business. This, however, is not the most effective approach as the non-privileged employees are usually unheard and their opinions are often discarded.

Democratization within corporations is essential to lay a strong foundation for future innovation explorations that will prevail in the coming years. Corporations cannot fully 
rely on selective employees and management systems that limit the organization's potential by ignoring the intellectual capacity on their human resources. Companies must embrace a democratic process to consolidate knowledge and transform it into meaningful and applicable innovations through corporate entrepreneurship and intrapreneurship initiatives for all. However, to apply such democratization strategies it is important first to identify the human recourses willing and able to innovate, to tackle lack of confidence on those with insecurities, to overcome personal interests, and to manage the ego of the senior managers primarily.

\section{Utilization of human intellectual capital via corporate entrepreneurship and intrapreneurship}

Corporate entrepreneurship and intrapreneurship is premised upon the utilization of people's, goals, drives and intellectual capital towards their transforming it into corporate entrepreneurial assets. To identity, develop and generate such assets, it is imperative to identify and measure the degree of intellectual capital that resides in an organization and the degree of the organizational infrastructure to support it. Intellectual capital is a relatively new term in the field of business management comprised from the intangible assets of knowledge, skills and information [1]. Intellectual Capital or Human Intellectual Capital (HIC) can de defined with various terminologies, but the essence primarily revolves around the knowledge, expertise, brain power and other aspects within an organization, which is quite complex to size and measure [2]. Over the last ten years there has been tremendous effort to utilize human intellectual capital and its impact in the creation of new corporate business activities.

Organizations today divert efforts and resources towards the transformation of 'employee experience' to 'human experience', by understanding and acknowledging the aspirations of employees and by embracing the democratic workforce concept. Deloitte highlights three domains of change towards the human experience in a $3 \mathrm{X} 3$ matrix with rows the futures of workforce, the organization and the HR, and with columns the refresh, rewire and recode effort needed to change the status quo in the organizational world (Fig. 1) [3].

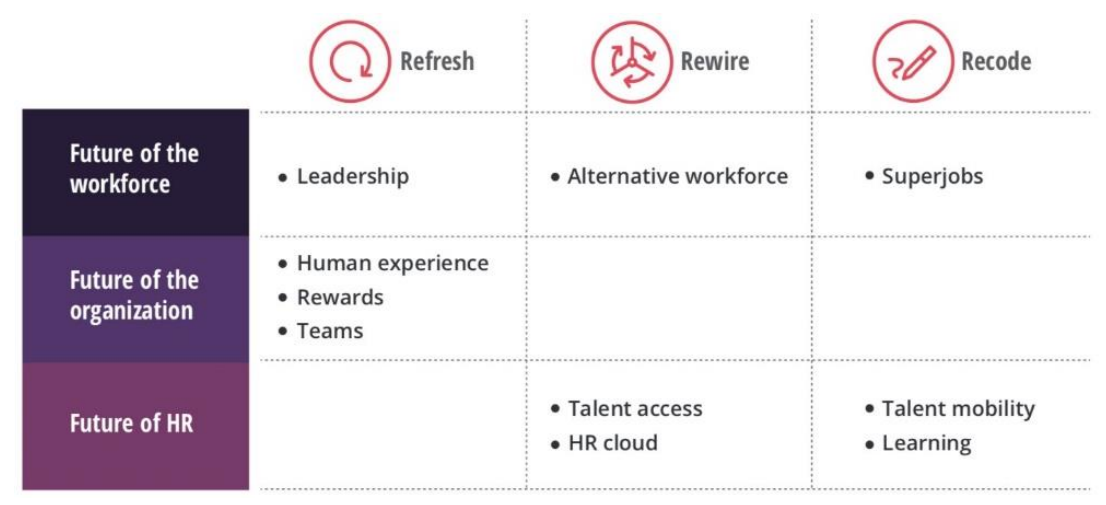

Fig. 1. Three domains for reinvention with approaches to change [3]. 
The elements that compose the matrix contribute towards improving the human intellectual capital concept for a shared, organizational and the employee's, development benefit.

\section{Shared Value Innovation and Operations Optimization}

Shared value innovation is an innovational dimension which integrates the shared benefits organizations and society can be obtained by working under a co-evolutionary philosophy. Effective intellectual capital utilization can lead to shared value innovation and open up new markets [4]. As the employees are part the society, their knowledge on improving the effectiveness of the company in both operations' management and new product/service development, returns back to the society in which they belong. The effective communication of such concept enables the transformation of the organization's workforce into corporate entrepreneurs where everyone has the ability, option and opportunity to make a difference for the organization, themselves and the society above all. The world is improving when the people improve it, and since not all people have the financial and organizational power to do it, this can be achieved with the proper utilization of their knowledge.

Figure 2 presents this integration of the company, market, society and the employees through intellectual capital on delivering shared value innovation under a co-evolutionary and co-developmental philosophy. The circular flow of knowledge is originated by the employees themselves. Through corporate entrepreneurial and intrapreneurial support they generate new intellectual capital-based products and services for the market to reach the society. The circle continues as the society inspires them with new ideas that ignite this repetition.

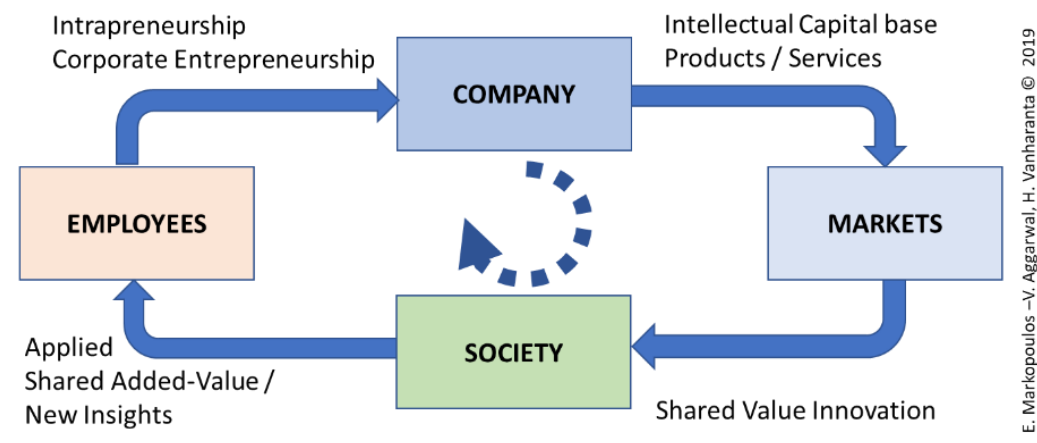

Fig. 2. Creation of shared added-value innovation for the society.

The effective support on such a circular shared value innovation approach impacts the success of the human intellectual utilization a company has. It is very difficult to measure the degree of human intellectual capital in an organization without the infrastructure needed for the employees to present their knowledge and apply it as well. The human intellectual value of an organization is related with the success employees record on transforming their knowledge into organizational benefits either with new products and services or with organizational optimization procedures and activities. 


\section{Democratizing corporate Entre- and Intrapreneurship}

Industry data (shown in Fig. 3), indicates significant organizational benefits that can derive from highly engaged employees [5]. Engaged business units increase the profitability by $21 \%$ [6]. However, to achieve such results it is important to provide the freedom and the space where employees can contribute to such a goal.

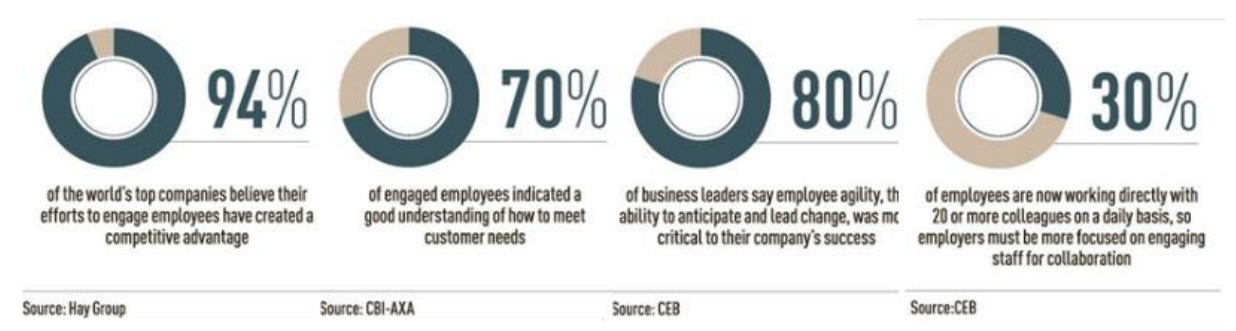

Fig. 3. Employee engagement organizational benefits [5].

Practical, and actual, freedom of speech is essential for the transformation of the tacit knowledge into explicit knowledge. However, there are major significant barriers that need to be managed first, mostly dealing with effective leadership. Authentic leaders motivate and support employees to actively and effectively commit, share and communicate their knowledge. Irrespective of the capability, maturity or capacity, it is imperative for companies to operate and flourish within a corporate culture that recognizes, acknowledges and respects the employees' knowledge and ideas once properly stated. As people do not lack creativity, intelligence or passion, it is mainly the corporate culture they operate into that limits their charismatic nature and their critical thinking.

In this effort, freedom of speech can be an Aristotelian knowledge driver from observation, to experimentation and from learning to wisdom [7]. The ability of people to share their knowledge makes them better observers in their attempt to justify and communicate their ideas to others. This systematic observation is the inception to the generation of wisdom where reasoning is the predominant factor of the associated thinking. Employees who believe their voice is heard are five times more likely to feel empowered and perform at the highest potential [8]. Y-Theory believes employees are not passive and companies should provide ample opportunities and room for employee's development to harness their intellect and channelize it towards meeting strategic organizational goals [9]. Other scholars propose the $\mathrm{Z}$-Theory which addresses human needs like belongingness, affiliation and trust [10]. Both theories set their based on the coexitance of employees and organizations through the freedom to transform their knowledge into action. Such approaches on employee engagements have as common denominator the democratization of knowledge. Freedom of speech is a classic democratic characteristic in societies which can also be applied in corporations.

Over the last decade, there has been a knowledge democratization movement as corporations begin to realize the value and impact of intellectual capital that resides within 
them. Several management models, theories and frameworks have been developed to manage knowledge elicitation for innovation management and operations optimization, while others directly deal with the democratization concept. Such a model is the Company Democracy Model (CDM) designed on the applied philosophical principles. The model integrates several democratic values that contribute to ethical and effective utilization of the human intellectual capital [11].

CDM operates through an evolutionary process framework [12], which is based on the ancient Hellenic wisdom of the Delhpic Maxims. The model applies several maxims but mostly the 'Know Thyself', 'Metron Ariston'and 'Miden Agan' to control selfawareness, ego and exaggeration [13]. CDM uses ontologies and taxonomies to classify organizational knowledge [14]. The model works in a spiral flow which continuously turns tacit knowledge into explicit [15]. Another model which also promotes democratic knowledge creation and utilization and is aligned with the CDM is the co-Evolute methodology [16]. The base idea of the model evolves on the concept that organizations can support their employees' personal growth, vision and development in order to improve the core competencies and both sides [17].

\section{The Applied DeCEIM Structure}

Based on the principles of the Company Democracy Model (CDM), the Democratic Corporate Entrepreneurial and Intrapreneurial Model (DeCEIM) can be generated by altering the CDM towards a more entrepreneurial dimension for the creation of new corporate ventures. The DeCEIM sustains the levels and philosophy of the CDM which start from the organizational knowledge elicitation to its total transformation into corporate business units, startups or spin-offs (shown in Fig. 4). The first three levels of the DeCEIM follow the concepts of the relevant levels of the CDM and emphasize on the identification of the knowledge and the maturity of the employee. The other three emphasise on the entrepreneurial dimension and the knowledge evolution.

Specifically, the first level creates a culture where knowledge is selected continuously and unbiased by all employees. Engagement motives are given for all to participate in this organizational culture. A very brief business planning is required mostly on the benefits of the idea/knowledge and less on the financial or technical dimension. On level two, the ones whose knowledge contributions have been selected to evolve are supported with entrepreneurial training and the proper experts to develop their ideas furthermore into full and well thought business plans. The third level implements the idea into new organizational product or service and launches it in the markets to judge it. The degree of success will determine if the next levels will be followed.

Upon the desired success, the organization transforms the new product or service into an innovative new business unit or product line. The innovation remains within the organization but operates as a different organizational internal product or service line. The success of level four moves the product/service to level 5 where an organizational spin off is created. It is the stage where the product/service is considered mature and strong enough to get detached from the organization and be managed as a separate organization but within a distance from the base. The effectives of level five brings the product or service to level 6 where the spin-off is fully detached from the organization and becomes an independent company within the group of companies of 
the organization. It is the stage where the product or service expanded its functionality, client base, partnerships, etc and can totally stand in the market on its own.

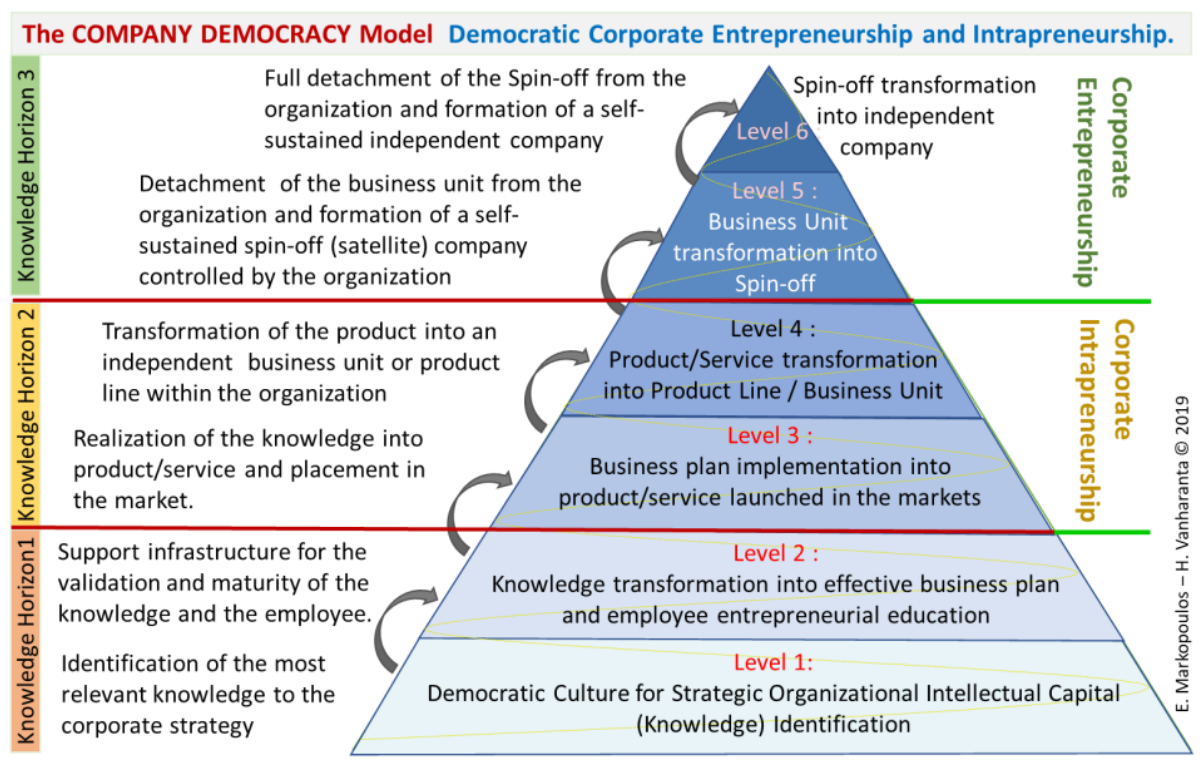

Fig. 4. The Applied DeCEIM Structure with the detailed activities

The organizational commitment on the DeCEIM on the knowledge utilizations is stronger in every dimension. Financial, organizational and administrative supports is fully provided, however the evaluation of the knowledge that enters DeCEIM is more demanding and rigorous. It must be noted that utilization and transformation of the organizational knowledge does not stop at level 3 where the prototypes are developed and successfully operate. Upon such success, organizations must target reaching each higher level where new corporate business units, product lines or spinoffs are created.

DeCEIM practically divides the evolution of the knowledge from an idea to an actual independent organization. However, there is another point of view in this evolution which can be extended into three knowledge maturity stages, or horizons. In the first stage the knowledge is transformed into a complete business plan (levels 1,2), in the next the idea enters the market and obtains sustainability via corporate intrapreneurship (levels 3,4 ), and the third stage detaches the operations of the idea from the organization giving it business independence, via corporate entrepreneurship (levels 5,6). It is a journey from the stage of today to the stages of tomorrow.

\section{Alignment of the DeCIEM with the McKinsey Horizons of Innovation}

This triadic staged evolution of the DeCEIM horizons can be related with the McKinsey Horizons Model for organizational competitiveness. 
In DeCEIM, the screening of ideas and their implementation over a time period must be related with the strategic vision of the organization. What is possible might not be feasible. Feasibility can be related to the expected success of a business initiative in specific time periods. McKinsey's 3 Horizon Model is premised upon addressing growth and innovation by assessing potential opportunities for growth in future without neglecting the performance of the present [18]. The model divides the timeframe into three horizons ranging from the core business (short-term) to the future business opportunity (long-term), with an intermediate horizon that acts a transition phase for the implementation of the innovation (shown in Fig. 5).

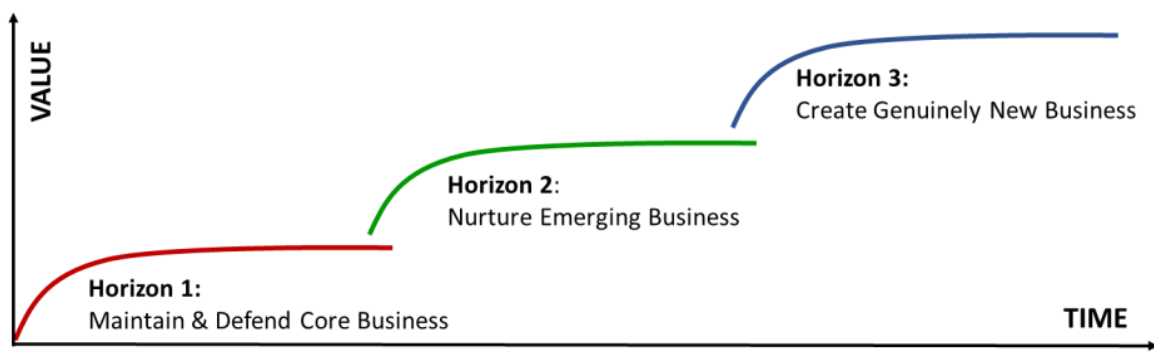

Fig. 5. McKinsey's 3 Horizon Model representing the three horizons of growth.

Horizon 1 refers to the core activities, assets and business of an organization. This horizon is responsible for activities that provide the current best profits. Horizon 2 refers to the emerging businesses, entrepreneurial ventures and opportunities that could result into future profits via investments. Horizon 3 refers to the creation of new businesses and opportunities that do not currently exist but can be achieved, with the activities of horizon 2, to create uncontested market spaces, or Blue oceans [19].

It is imperative to acknowledge and undertake a gap analysis between horizon 1 and horizon 3 to identify horizon 2 . There are conditions that must be satisfied in every transition process. Firstly, it is important to gather a deep understanding of the core business (horizon 1) and key assets that drive revenue. As the business environment constantly changes with a dynamic nature, an organization can either imagine how to compete in horizon 1 or plan the desired future stage at horizon 3 through horizon 2, the bridge stage from the planning to the achieving.

A common denominator on the horizon's evolution equation is the quality of knowledge on understanding the current state, the future state and consequently what needs to be done in the intermediate stage. This corporate knowledge cannot be obtained effectively and accurately without the contribution of the organisation's human resources. It is the employees who are the driving force for the effective execution of business activities that take place in each horizon. Therefore, a collective understanding of the current and future state through the employees is imperative to propel the company towards growth and innovation by capitalizing on the knowledge the organization generates in the 3 horizons. 


\section{Implementing of the DeCEIM within the McKinsey Horizons}

The integration of the DeCEIM with the McKinsey Horizons can effectively be achieved with the utilization of the organization's intellectual capital that resides in the DeCEIM knowledge horizon 1. The democratic culture in DeCEIM horizon 1 identifies and engages the employees that can participate towards the realization of the McKinsey horizon 3. This implies that the vision will be divided into separate strategic goals and be achieved by competent and ambitious employees who are agile enough to drive this visionary change through their innovations and entrepreneurial journey within the DeCEIM. McKinsey horizon 2 involves the implementation of the strategic knowledge gained in horizon 1. The success of each initiative selected in horizon 1 at horizon 2 brings the organization one step closer to horizon 3. The degree of success of horizon 2 determines the degree of success in time and goals of horizon 3. Figure 6 highlights the role of the DeCEIM Horizons (levels) in each McKinsey Horizon.

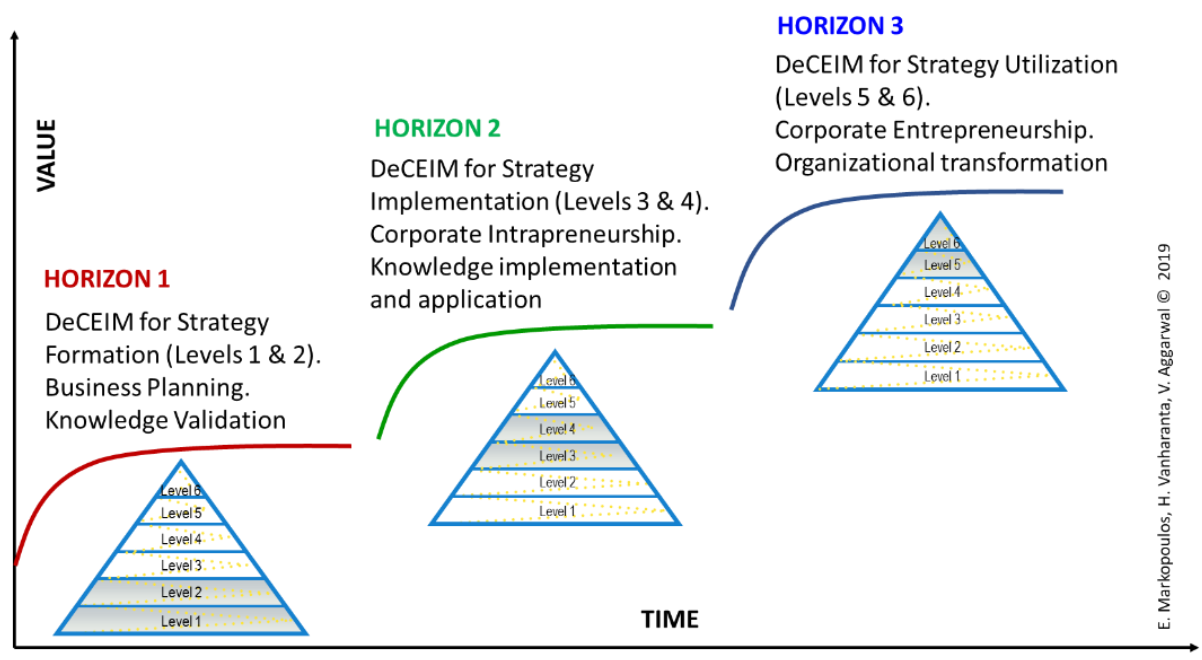

Fig. 6. A transition flow for companies under McKinsey's 3 horizon model by using the DeCEIM.

The horizon's transitions are best achieved once the organizations know the desired stage (McKinsey horizon 3). Knowing what shall be archived helps direct the activities of DeCEIM horizon 1 towards the identification of the intellectual capital that will be selected and matured in horizon 1, implemented in horizon 2 and integrated in horizon 3. A second condition to achieve McKinsey horizon 3 more effectively and minimize risk of corporate failure, is to decompose the vision of level three into quite small segments where the human recourses are able to direct their knowledge and skills through DeCEIM. Gatherings small knowledge contributions helps employees come up with more focused and valid knowledge and work (Fig. 7).

It must be noted that in the proposed horizon transition process there can be knowledge initiatives and projects that even if they could be well selected and matured 
in the DeCEIM levels 1 and 2, might not succeed in levels 3 and 4. This means that not all activities of McKinsey horizon 1 can move into horizon 2. This might either leave the goal on horizon 3 incomplete or extend the completion time until all the elements are in place.

Another effect this approach has is the impact of the McKinsey horizon 2 to horizon 3. As the elements of horizon 2 assimilate and integrated when reaching horizon 3 , the new corporate vision, strategy might be different from the one designed in horizon 1.

This difference can be positive or negative based on the quality, the time, the innovation and the market's response indicated on each activity of horizon 2 . However, it is up to the organization to accept such deviations or insist on the original goal over time. This transition flow within the McKinsey's 3 horizon, allow companies to learn from the activities of horizon 2 that could not sustain value, but also leverage upon such activities in the emerging business landscape that might be crucial for future strategy formulation and implementation.

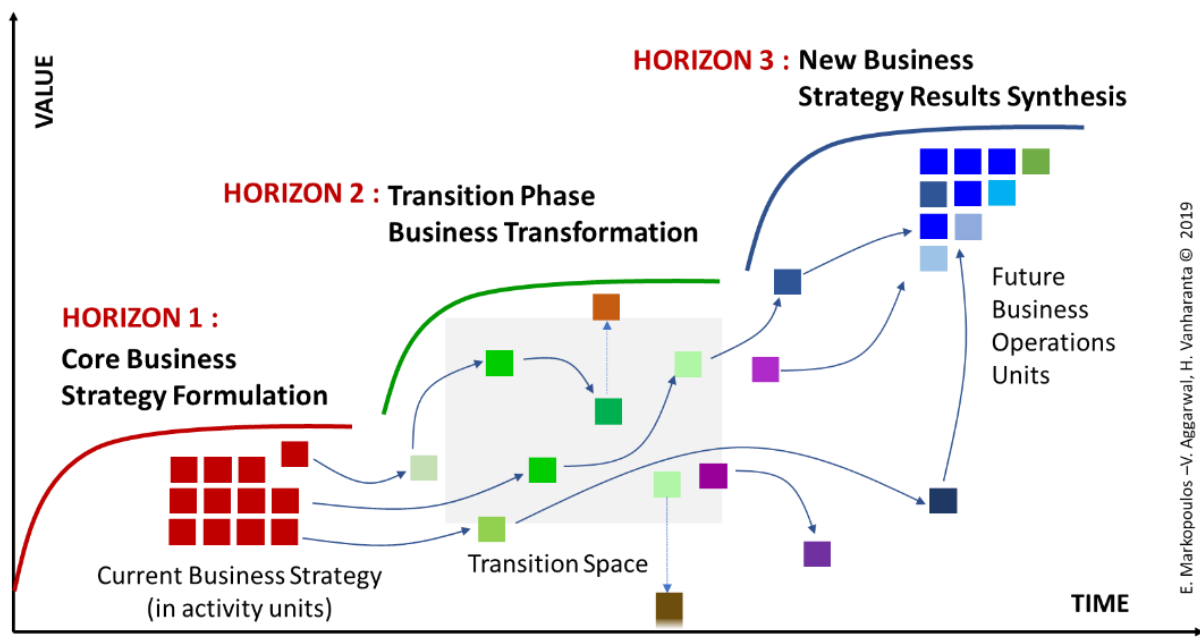

Fig. 7. A transition flow for companies under McKinsey's 3 horizon model by using the DeCEIM.

\section{Conclusions}

The integration of the Company Democracy Model's DeCEIM Horizons and the McKinsey's 3 Horizon model can generate a democratic business transformation strategy based on the practical utilization of the organization's human intellectual capital. Pre-conditions for such a strategy include the establishment of an ethical knowledge share culture for the two models to co-operate. Based on that, the Company Democracy Model, through DeCEIM, is evolved over the McKinsey's 3 horizon model, allowing the model to move from the current activities (horizon 1), to business transformation via corporate intrapreneurship (horizon 2) and to new and future market development via corporate entrepreneurship (horizon 3). Post conditions is the post implementation 
analysis of each maturity journey towards repeating the process for higher achievements and continuous development.

This knowledge driven democratic framework enables organizations to succeed, create and sustain competitive advantage by becoming confident in horizon 1, competitive upon horizon 2 and innovative upon horizon 3, within a knowledge based democratic corporate environment.

\section{References}

1. Stewart, T.A., Loose S.: Your Company's Most Valuable Asset: Intellectual Capital. Fortune, 130, pp 68--74 (1994).

2. Abdolmohammadi, M.J.: Intellectual capital disclosure and market capitalization. Journal of Intellectual Capital. 6, 3, pp 397--416 (2005).

3. Deloitte https://www2.deloitte.com/insights/us/en/focus/human-capital-trends.html

4. Markopoulos E., Vanharanta. H.: The Company Democracy Model for the Development of Intellectual Human Capitalism for Shared Value, Procedia Manufacturing, vol 3, pp 603-610 (2015)

5. Raconteur. .https://www.raconteur.net/hr/empower-and-inspire-the-right-people-and-theywill-excel

6. Gallup. https://www.gallup.com/workplace/236366/right-culture-not-employee-satisfaction.aspx

7. Oravec C.: Observation' in Aristotle's Theory of Epideictic. Philosophy \& Rhetoric, JSTOR, vol. 9, no. 3, pp 162--174. (1976),

8. Salesforce Research. https://c1.sfdcstatic.com/content/dam/web/en_us/www/assets/pdf/datasheets/salesforce-research-2017-workplace-equality-and-values-report.pdf

9. Versita. https://www.degruyter.com/downloadpdf/j/cris.2013.2013.issue-2/cris-20130012/cris-2013-0012.pdf

10. Morden, T.: Principles of strategic management. Routledge, London (2017).

11. Markopoulos E., Vanharanta H.: Democratic Culture Paradigm for Organizational Management and Leadership Strategies - The Company Democracy Model. Proceedings of the 5th International Conference on Applied Human Factors and Ergonomics AHFE 2014 (2014).

12. Vanharanta H., Markopoulos E.: Creating a Dynamic Democratic Company Culture for Leadership, Innovation, and Competitiveness. 3rd Hellenic-Russian Forum. Sept.17. (2013).

13. Parke H., Wormell D.: The Delphic Oracle, Basil Blackwell, vol. 1, p. 389 (1956).

14. Paajanen, P., Piirto, A., Kantola, J., Vanharanta, H.: FOLIUM - Ontology for Organizational Knowledge Creation. 10th World multi-conference on systemics, cybernetics, and informatics. (2006).

15. Nonaka I., Takeuchi H., The Knowledge-Creating Company: How Japanese Companies Create the Dynamics of Innovation, New York, Oxford University Press (1995).

16. Kantola, J., Vanharanta, H., Karwowski, W.: The Evolute System: A Co-Evolutionary Human Resource Development Methodology. In the International Encyclopedia of Ergonomics and Human Factors. Karwowski, W., CRC Press. (2006).

17. Kantola J., Imran F.: Evolute system approach and identification of talent. Proceedings of 86 th IASTEM International Conference, Rawalpindi, Pakistan, 29th -30th October 2017, pp 11-16 (2017)

18. McKinsey. https://www.mckinsey.com/business-functions/strategy-and-corporate-finance/our-insights/enduring-ideas-the-three-horizons-of-growth

19. Kim W. C., Mauborgne R.: Blue ocean strategy. Boston, Mass. Harvard Business School Press (2005) 